\section{Conditioned taste aversions as a function of the number of CS-US pairs*}

\author{
ROBERT M. BRACKBILL and KENNETH H. BROOKSHIRE \\ Franklin and Marshall College, Lancaster, $\mathrm{Pa} .17604$
}

Rats were given two-choice water-saccharin preference tests after saccharin had been paired with apomorphine hydrochloride for $1,2,4,8$, or 16 trials. The results indicated that the conditioned aversion is quite pronounced after only two trials and that suppression of single stimulus consumption of the CS substance during successive conditioning trials is not perfectly related to the preference data.

It has been amply demonstrated that animals will learn to avoid gustatory stimuli that have been associated with toxicosis (induced by X-irradiation, cyclophosphoamide, lithium chloride, apomorphine hy drochloride, etc.). Furthermore, there is evidence that, in some respects, such learning is remarkably more easily formed than is learning involving associations in other sensory modalities. Thus, taste aversions have been detected when the CS-US interval was $7 \mathrm{~h}$ (Revusky, 1968) or even $12 \mathrm{~h}$ (Smith \& Roll, 1967), whereas effective CS-US intervals in conditioning studies using stimuli in other sensory modalities seem to be limited to a few seconds (Kimble, 1961). Moreover, after a single prolonged taste-aversion conditioning trial, Garcia, Kimeldorf, \& Koelling (1955) found a taste aversion to saccharin which failed to show signs of extinction for 10 (unreinforced) test days.

From such considerations it would seem reasonable to suppose that variation of other parameters of conditioning would confirm the efficaciousness of the associations formed between taste stimuli and toxicosis. For example, one would expect that the function relating the avoidance $\mathrm{CR}$ to number of CS-US pairings would be very steep and would reach asymptote quickly. Such a function often has been assumed but rarely has been investigated. Certainly, there is evidence that aversive taste conditioning can be detected in two-choice test situations after one (McLaurin, 1964; US was X-irradiation) to three (Wittlin \& Brookshire, 1968 ; US was apomorphine) trials, but very few studies have been reported in which the number of CS-US pairings served as an independent variable. Garcia, Ervin, \& Koelling (1966), using a within-groups design and a single-stimulus test situation (where the conditioned aversion was pitted

* This study was supported by Grants GB-3434 and GY-5906 from the National Science Foundation. against a very high thirst drive), found progressively greater aversion to a saccharin CS from one to four CS-US pairings, and they obtained no indication that an asymptote had been reached. Rozin (1969) found a progressively greater aversion to saccharin or casein hydrolysate when either was paired with intubated $\mathrm{LiCl}$; again, no clear asymptote was reached. Neither of these studies used a procedure which provided optimal conditions for studying a trials effect: For example, Rozin's Ss were conditioned and tested under only a 5-h thirst drive, and the preference function generated (calculated in terms of percentage of total ingestion) may not have been an accurate reflection of degree of learning; further, preference tests were interspersed between conditioning trials, and, thus, each successive test reflected a confounding of learning and extinction processes.

The present study investigated saccharin aversion as a function of CS-US pairings using a between-groups design. The Ss received a two-choice preference test under $23 \mathrm{~h}$ of water deprivation; thus, Ss did not have to remain thirsty in order to avoid the $\mathrm{CS}$, and yet they were highly motivated to drink. The test occurred only after the last conditioning trial for each $S$ and, therefore, did not reflect any possible extinction effects. Under these conditions, a more abrupt learning curve was expected, consistent with those studies cited above, where taste-aversion learning has been shown to be formed quite rapidly.

Forty Charles River Sprague-Dawley rats were used as Ss. At the beginning of the experiment the animals were 51 days old and weighed an average of $215 \mathrm{~g}$. The animals were housed in test boxes which had three adjacent holes, $2 \frac{1}{2}$ in. apart, and clips for the insertion of graduated Richter tubes.

For 5 days prior to the beginning of the experiment, all 40 Ss were placed on an $11 \frac{1 / 2}{-} \mathrm{h}$ deprivation schedule, receiving distilled water for $1 / 2 \mathrm{~h}$ in the

\section{METHOD}

morning and again $12 \mathrm{~h}$ later. On Day 1 of the experiment, $11^{1 / 2} \mathrm{~h}$ after the last water-drinking period, all Ss experienced the first conditioning trial. For the first $15 \mathrm{~min}$ of the session, all Ss were exposed to $0.1 \%$ saccharin in a Richter tube, which was placed in the middle position of the preference boxes. Thirty minutes after the tubes had been removed, the Ss were given an intraperitoneal injection of either apomorphine hydrochloride or isotonic saline (placebo). Experimental animals received $15 \mathrm{mg} / \mathrm{kg}$ body weight of apomorphine solution $(5 \mathrm{mg} / \mathrm{ml})$; control Ss received an equal volume of placebo. The $40 \mathrm{Ss}$ were subdivided into five groups of eight animals each (four experimental Ss and four control Ss). These groups received $1,2,4,8$, and 16 conditioning trials, respectively. Conditioning trials were spaced $24 \mathrm{~h}$ apart, but Ss were only $11^{1 / 2} \mathrm{~h}$ thirsty, since they continued to receive $1 / 2-h$ free access to water midway between each trial.

Twenty-four hours after the last conditioning trial, each $S$ received, for 3 days, a two-choice preference test between $0.1 \%$ saccharin (CS) and distilled water. The preference tests lasted for $1 \mathrm{~h}$ per day. In order to control for possible position biases, the two Richter tubes were rotated daily, occupying the two lateral holes of the box.

\section{RESULTS AND DISCUSSION}

All two-choice preference data were converted into "preference scores," based upon percentage of saccharin ingested (milliliters) divided by total consumption of water and saccharin combined.

Figure 1 shows that the experimental groups which received 2 , 4, 8, and 16 trials had a reduced preference for saccharin. A single CS-US pairing did not produce a reduction in preference for saccharin. These results emerged statistically in an overall analysis of variance (mixed design, with repeated measures). There was an overall significant difference between experimental and control groups $(F=46.6, \mathrm{df}=1 / 30, p<.01)$, and the number of conditioning trials also was significant as a primary source $(\mathrm{F}=3.76, \quad \mathrm{df}=4 / 30, \mathrm{p}<.025)$. In addition, there was a significant interaction between injection groups (experimental and control) and the number of CS-US pairings $(F=3.71$, $\mathbf{d f}=4 / 30, \mathbf{p}<.025)$, and by Scheffé tests it was determined that the significant interaction was the result of a nonreliable difference between experimental and control groups following a single CS-US pairing.

In order to determine if there was a relationship between number of CS-US pairings and the amount of CS 


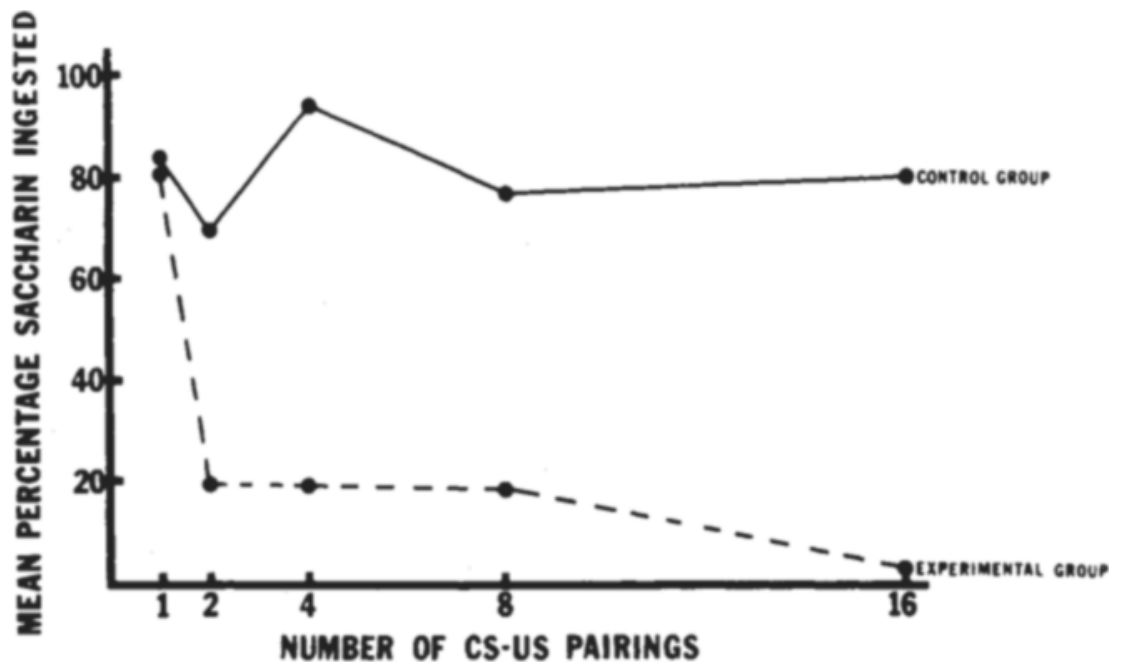

Fig. 1. Preference for a saccharin CS as a function of number of CS-US pairings.

ingested during the conditioning phase of the study, the number of milliliters of saccharin consumed on the last conditioning day for the $2 \cdot, 4 \cdot, 8 \cdot$, and 16-trial $\mathrm{E}$ and $\mathrm{C}$ groups was determined. These are presented in Table 1. By a two-way analysis of variance, experimental animals ingested significantly less fluid than control Ss $(F=20.8, \quad d f=1 / 24$, $\mathrm{p}<.01$ ), but it is clear from the table that final-trial ingestion is relatively stable for Ss in the experimental group despite wide variation in number of CS-US pairings. Both number of CS-US pairings $(\mathrm{F}=1.2, \mathrm{df}=3 / 24)$ and the interaction $\quad(F=2.2$, $\mathrm{d} \mathrm{f}=3 / 24$ ) were not significant-notwithstanding the apparent large change in ingestion, as a function of trials, by the control group. Of course, all E groups shown in the table ingested considerably less CS fluid than either $\mathrm{E}$ or $\mathrm{C}$ groups did prior to the first apomorphine injection (Trial 1), where mean milliliters ingested was $\mathbf{9 . 8 3}$.

It is puzzling when the final-trial CS ingestion during conditioning of the 2-day group (Table 1) and the

Table 1

CS Fluid Consumed (in ml) on Last Conditioning Day

\begin{tabular}{ccr}
$\begin{array}{c}\text { Number of } \\
\text { CS-US Pairings }\end{array}$ & E & \multicolumn{1}{c}{ C } \\
\hline 2 Day & 3.75 & 5.25 \\
4 Day & 3.25 & 6.25 \\
8 Day & 3.25 & 10.00 \\
16 Day & 2.50 & 11.00 \\
\hline
\end{tabular}

performance of the 1-day group during the preference test (Fig. I) are compared. Both data points represent the behavior of Ss toward the CS after a single CS-US pairing. Whereas the 1-day group showed no preference change relative to controls, the 2-day group showed an inhibition of CS drinking (after one CS-US pairing) which was essentially as great as that of the Ss in the 16-day group. This apparent discrepancy may be the result of a long-lasting $(24-\mathrm{h})$ residual effect of the apomorphine injection: Ss may still have been ill enough to manifest less overall drinking, even though they had not yet associated the illness with the gustatory cue. Some slight support for this interpretation is found when we calculate mean total fluid consumption for the first preference test day of $\mathrm{E}$ and $\mathrm{C}$ groups receiving one CS-US pairing (i.e., number of milliliters drunk of saccharin and water combined); the $\mathrm{E}$ group averaged $9.75 \mathrm{ml}$ and the $\mathrm{C}$ group $12.50 \mathrm{ml}$.

In any case, it is apparent that after only two CS-US pairings a very strong aversion to saccharin has occurred, almost as strong as that obtained after 16 pairings. Since saccharin is a highly preferred substance, it is not adequate to explain away these results as due to an inevitable "floor" effect (where the nonreliable differences between experimental groups is judged to be an artifact of a preference function which approaches an absolute zero point even in control Ss): The impressive feature of Fig. 1 is that rats will show a very pronounced aversion to a substance that they normally prefer and that this aversion occurs in precipitous fashion after only two CS-US pairings.

There seems to be a prevailing point of view which suggests that demonstration of a gradual avoidance function, as number of CS-US pairings is increased, particularly supports a learning interpretation of this class of phenomena. But, of course, a gradual decrement in ingestion of the CS substance is equally consistent with interpretations suggesting other processes related to conditioning as well (e.g., sensitization). If taste aversions following association of a gustatory $\mathrm{CS}$ with toxicosis are to be considered to be Pavlovian conditioning, the argument must rest on more persuasive data using different designs (cf. Rozin, 1968). While the present experiment was not undertaken with this goal in mind, it is possible to argue that the absence of a preference change in the 1-day experimental group, despite an apparent decreased thirst and despite a diminution of preference for the CS by the other experimental groups, at least permits us to dissociate taste aversions obtained in a two-choice situation from any "hangover" effects of the previous day's apomorphine injection.

\section{REFERENCES}

GARCIA, J., ERVIN, F. R. \& KOELLING R. A. Learning with prolonged delay of reinforcement. Psychonomic Science, $1966,5,121-122$.

GARCIA, J., KIMELDORF， D. J., \& KOELLING, R. A. Conditioned aversion to saccharin resulting from exposure to gamma radiation. Science, 1955, 122 , 157-158.

KIMBLE, G. A. Hilgard and Marquis Conditioning and learning. (2nd ed.) New York: Appleton-Century-Crofts, 1961.

McLAURIN, W. A. Postirradiation saccharin avoidance in rats as a function of the interval between ingestion and exposure. Journal of Comparative \& Physiological Psychology, 1964, 57, 316-317.

REVUSKY, S. H. Aversion to sucrose produced by contingent $\mathrm{X}$-irradiation: Temporal and dosage parameters. Journal of Comparative \& Physiological Psychology, 1968, 65, 17-22.

ROZIN, P. Specific aversions and neophobia resulting from vitamin deficiency or poisoning in half-wild and domestic rats. Journal of Comparative \& Physiological Psychology, 1968, 66, 82-88.

ROZIN, P. Central or peripheral mediation of learning with long CS-US intervals in the feeding system. Journal of Comparative \& Physiological Psychology, $1969,67,421-429$.

SMITH, J. C., \& ROLL, D. L. Trace conditioning with $\mathrm{X}$-rays as the aversive stimulus. Psychonomic Science, 1967, 9, 11-12.

WITTLIN, W. A., \& BROOKSHIRE, K. H. Apomorphine-induced conditioned aversion to a novel food. Psychonomic Science, 1968, 12, 217-218. 